\title{
Factors affecting the nodule size of asymmetric PMMA membranes
}

\author{
Ruoh-Chyu Ruaan ${ }^{\text {a,*}}$, Hsuan-Liang Chou ${ }^{\text {a }}$, Hui-An Tsai ${ }^{\text {a }}$, \\ Da-Ming Wang ${ }^{\mathrm{b}}$, Juin-Yih Lai ${ }^{\mathrm{a}}$ \\ a Membrane Research Laboratory, Department of Chemical Engineering, Chung Yuan University, Chung Li 32023, Taiwan, ROC \\ ${ }^{\mathrm{b}}$ Department of Chemical Engineering, National Taiwan University, Taipei 10617, Taiwan, ROC \\ Received 14 March 2000; received in revised form 25 October 2000; accepted 25 October 2000
}

\begin{abstract}
Several factors that may affect the surface nodule size of a polymeric membrane were under investigation. The increase of polymer concentration and molecular weight were found to increase the surface nodule size. The increase of casting temperature also resulted in an increase in nodule size. These results supported that the radius of gyration and the collision frequency between polymer chains were the key factors affecting the nodule size. However, when the radius of gyration was reduced by the use of a poor solvent or by pre-adding nonsolvent in the casting solution, the surface nodule size increased. It suggested that there existed other factors affecting the nodule size on membrane surface besides the gyration radius and the collision frequency of polymer chains. In this study, we found in most cases that the surface nodule size decreased along with the surface tension difference between the casting solution and the coagulant. To demonstrate the effect of surface tension, we examined the nodule size inside the membranes where the nodule formation was not significantly affected by the interfacial tension. Opposite to what was observed on the surface, the nodule size increased with the solvation power of the solvent. This result suggested that it was the interfacial tension that overpowered the gyration radius in affecting the surface nodule size. (C) 2001 Elsevier Science B.V. All rights reserved.
\end{abstract}

Keywords: Nodule size; Surface tension; Gyration radius; PMMA

\section{Introduction}

Asymmetric membrane formed by wet phase inversion method usually owns a dense skin layer and porous sublayers. The permeability and selectivity of an asymmetric membrane are mostly determined by its skin layer [1]. Polymer nodules are tightly packed in the skin layer [2]. The permeability of the skin layer was shown related to the surface roughness and the nodule size in the skin layer [1]. There were some

\footnotetext{
${ }^{*}$ Corresponding author. Tel.: +886-3-456-171.

E-mail address: ruaan@mbox.cycu.edu.tw (R.-C. Ruaan).
}

reports on how the surface nodule size of a symmetric membrane formed by dry process was affected. Kesting [2] has suggested that the surface nodule size was affected by the surface tension of the casting solution. Khulbe et al. [3,4] found that the surface nodule size was affected by the boiling point of the solvent as well as the thickness of the membrane. Hamza et al. [5] found that the surface nodule size of a sulfonated poly(2,6-dimethyl-1,4-phenylene oxide) membrane could be varied by adjusting the composition of its solvent system. They suggested that the increase of nodule size was due to the increase of polymer-solvent interaction. However, there was limited report on the 
factors affecting surface nodule size of asymmetric membranes formed by wet phase inversion method. The only information obtained was that the nodular structure was affected by the phase separation mechanism during membrane formation [6,7].

In this study, we monitored the nodule size on the surface of polymethylmethacrylate (PMMA) membranes through scanning electron microscope (SEM). The effects of polymer concentration, molecular weight of PMMA, casting temperature, solvation power of casting solvent and the amount of nonsolvent additives in casting solution were under investigation. From these results, we were able to discuss how and why the surface nodule size would be altered.

\section{Experimental}

\subsection{Materials}

Poly(methyl methacrylate), of which the molecular weights are 33,500,140,000 and 314,400, were purchased from Aldrich Chemical Co. The solvents, $\mathrm{N}$-methyl pyrrolidinone (NMP) and dimethyl sulfoxide (DMSO) were of reagent grade and used without further purification. Distilled water was used as the nonsolvent.

\subsection{Membrane preparation}

Nonsolvent was added in NMP to a concentration of $0,2,6$, or $10 \mathrm{v} / \mathrm{v} \%$. PMMA was dissolved in the above solvent mixture to form $12,15,18 \mathrm{wt} . \%$ casting solutions at 90,50 or $10^{\circ} \mathrm{C}$. The degassed casting solution was casted on a pre-warmed or pre-cooled glass plate to a predetermined thickness of $300 \mu \mathrm{m}$ by a Gardner knife, and then immersed in a 201 coagulation bath overnight. The coagulation bath was controlled at the same temperature as the casting solution. The obtained membranes were peeled-off and dried in a $90^{\circ} \mathrm{C}$ vacuum oven for $24 \mathrm{~h}$.

\subsection{SEM analysis}

The membrane structures were examined by a Hitachi (Model S4000) SEM. The membrane samples were fractured in liquid nitrogen and then coated with gold.

\subsection{Determination of nodule size}

Nodule size was estimated by examining the SEM image. The longest and shortest axes of each nodule were measured manually with the help of an image analysis software, Inspector, from Matrox electronic systems Ltd., Canada. The size of each nodule was calculated by the root mean square of the longest and shortest axes. The presented data was the average of 50 grains appearing in the SEM image.

\subsection{Determination of surface tension}

The surface tensions of PMMA casting solution and distilled water were measured at $25^{\circ} \mathrm{C}$ by the ring method using the Surface Tension Apparatus CBVP-A3 manufactured by Kyowa Interface science Co., Ltd., Japan.

\section{Results and discussion}

\subsection{Effect of polymer concentration on surface nodule size}

PMMA of various concentrations were casted at $90^{\circ} \mathrm{C}$ using water as the nonsolvent. The surface nodule size was measured through image analysis upon SEM surface images. Fig. 1 demonstrates the surface nodule of membranes casted at 12,15 , and $18 \mathrm{wt} . \%$ of PMMA in NMP. The first three rows in Table 1 show the dependence of surface nodule size on polymer concentration. It was found that the surface nodule size increased slightly as the polymer concentration increased. Since higher polymer concentration increased the chance of interchain entanglement, this result suggested that the nodule formation was related to polymer aggregation.

\subsection{Effect of molecular weight of PMMA molecules on surface nodule size}

PMMA of different molecular weights were dissolved in NMP to form $18 \mathrm{wt} . \%$ casting solutions. The surface nodule sizes were compared, which are shown in Table 1 and Fig. 2. It was found that the surface nodule size increased tremendously when the 


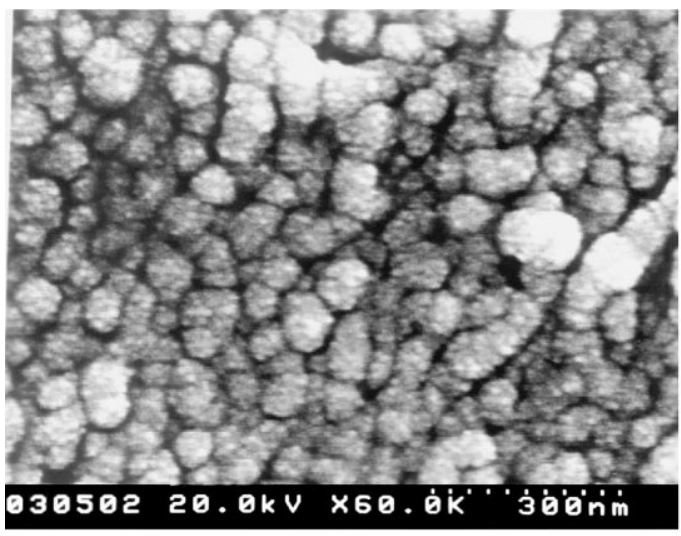

(a)

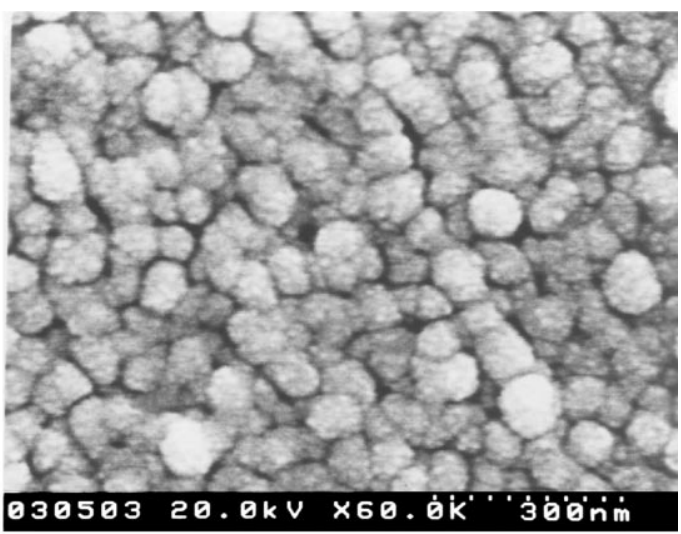

(b)

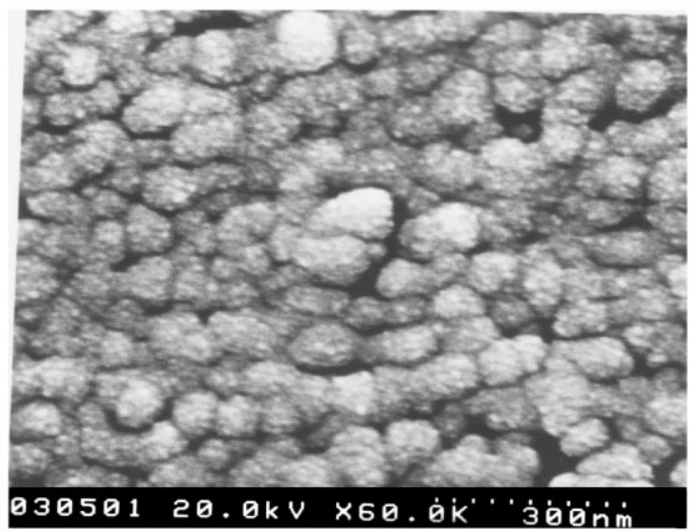

(c)

Fig. 1. SEM images of the surface nodules of PMMA membranes casted at various polymer concentrations: (a) $12 \mathrm{wt} \%$, (b) $15 \mathrm{wt} . \%$, and (c) $18 \mathrm{wt} . \%$ of PMMA dissolved in NMP and casted at $90^{\circ} \mathrm{C}$.

molecular weight increased from 33,500 to 140,000 . If we could assume that the probability of interchain entanglement was increased by the molecular weight, this result again indicated that the interchain entanglement was the predominant factor affecting surface nodule size.

\subsection{Effect of temperature on surface nodule size}

The gyration radius and the mobility of polymer chain will be increased at higher temperature. Subsequently, the chance of interchain entanglement can be increased by raising the casting temperature. PMMA/NMP solution was then prepared at $18 \mathrm{wt} . \%$, and casted at three different temperatures, 10, 50, and $90^{\circ} \mathrm{C}$. The dependence of surface nodule size on the casting temperature was shown in Table 1 and Fig. 3. Indeed, the nodule size at higher temperature was found larger than that at lower temperature. Together with the above results, the evidences tended to support that the probability of interchain entanglement dominated the surface nodule size.

\subsection{Effect of solvent power}

The probability of interchain entanglement can be affected by the polymer concentration, polymer mobility, and the gyration radius of the polymer chain. The gyration radius of a polymer in its good solvent is supposedly larger than that in a poor solvent. Therefore, the casting solutions formed by solvents of higher solvation power should result in membranes of 
Table 1

Sizes of surface nodules of PMMA membranes

\begin{tabular}{|c|c|c|c|}
\hline Temperature $\left({ }^{\circ} \mathrm{C}\right)$ & Casting solution, polymer/solvent & $\begin{array}{l}\text { Molecular weight } \\
\text { of PMMA }\left(M_{\mathrm{W}}\right)\end{array}$ & Nodule size $(\mathrm{nm})$ \\
\hline 90 & 12 wt.\% PMMA/NMP & 140,000 & $91.0 \pm 8.5^{\mathrm{a}}$ \\
\hline 90 & 15 wt.\% PMMA/NMP & 140,000 & $108.0 \pm 8.9^{*}$ \\
\hline 90 & 18 wt. \% PMMA/NMP & 140,000 & $130.0 \pm 11.2^{*}$ \\
\hline 90 & 18 wt.\% PMMA/NMP & 140,000 & $130.0 \pm 11.2^{\mathrm{a}}$ \\
\hline 90 & 18 wt. \% PMMA/DMSO & 140,000 & $142.0 \pm 8.6^{*}$ \\
\hline 90 & 18 wt.\% PMMA/NMP & 33,500 & $52.0 \pm 8.2^{\mathrm{a}}$ \\
\hline 90 & 18 wt. \% PMMA/NMP & 140,000 & $130.0 \pm 11.2^{*}$ \\
\hline 90 & 18 wt.\% PMMA/NMP & 140,000 & $130.0 \pm 11.2^{\mathrm{a}}$ \\
\hline 90 & 18 wt. $\%$ PMMA/98 vol. $\% \mathrm{NMP}+2$ vol. $\% \mathrm{H}_{2} \mathrm{O}$ & 140,000 & $138.0 \pm 5.9^{*}$ \\
\hline 90 & 18 wt. $\%$ PMMA/94 vol. $\%$ NMP +6 vol. $\% \mathrm{H}_{2} \mathrm{O}$ & 140,000 & $145.0 \pm 6.2^{*}$ \\
\hline 10 & 18 wt.\% PMMA/NMP & 140,000 & $57.0 \pm 6.1^{\mathrm{a}}$ \\
\hline 50 & 18 wt.\% PMMA/NMP & 140,000 & $83.0 \pm 6.6^{*}$ \\
\hline 90 & 18 wt.\% PMMA/NMP & 140,000 & $130.0 \pm 11.2^{*}$ \\
\hline
\end{tabular}

${ }^{a}$ Reference data set.

* $P<0.001$, when the set of data was compared with the reference under $t$-test.

larger nodule size. Adopting Hilderbrand and Hansen parameters for the solvent [8] and Hoy's method to estimate the solubility parameter for the polymer [9], we are able to calculate the solubility parameter difference between species $i$ and $j$ by the following formula:

$$
\Delta \delta_{i-j}=\left[\left({ }^{i} \delta_{\mathrm{d}}-{ }^{j} \delta_{\mathrm{d}}\right)^{2}+\left({ }^{i} \delta_{\mathrm{p}}-{ }^{j} \delta_{\mathrm{p}}\right)^{2}+\left({ }^{i} \delta_{\mathrm{h}}-{ }^{j} \delta_{\mathrm{h}}\right)^{2}\right]^{1 / 2}
$$

where ${ }^{i} \delta_{\mathrm{d}}$ is the contribution of dispersion force to the solubility parameter of species $i,{ }^{i} \delta_{\mathrm{p}}$ the contribution of polar force to the solubility parameter of species $i,{ }^{i} \delta_{\mathrm{h}}$ the contribution of hydrogen bonding

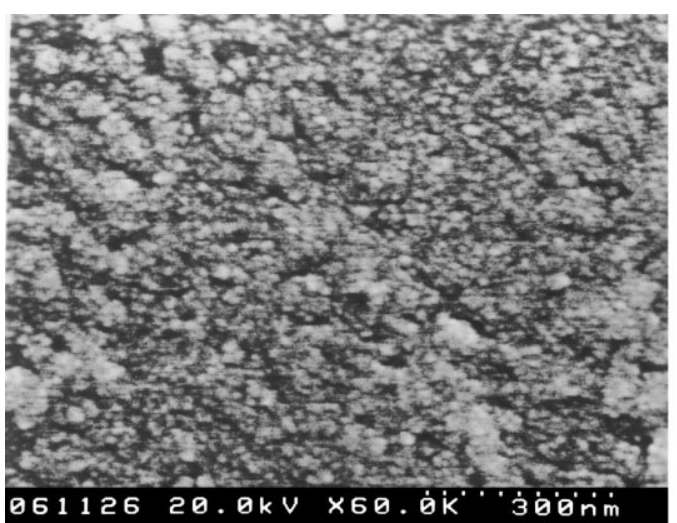

(a) to the solubility parameter of species $i$. According to the solubility factor differences listed in Table 2, the order of their solvation power towards PMMA was DMAc $>$ NMP $>$ DMSO. The surface nodules were then compared among PMMA membranes formed by these three different solvents. Fig. 4 shows the SEM images, and Table 1 gives the nodule size of the surface of PMMA membranes formed by different solvents, NMP, DMAc, and DMSO. It was interesting to find that the surface nodule of membranes formed by DMSO was slightly larger than that of NMP. The

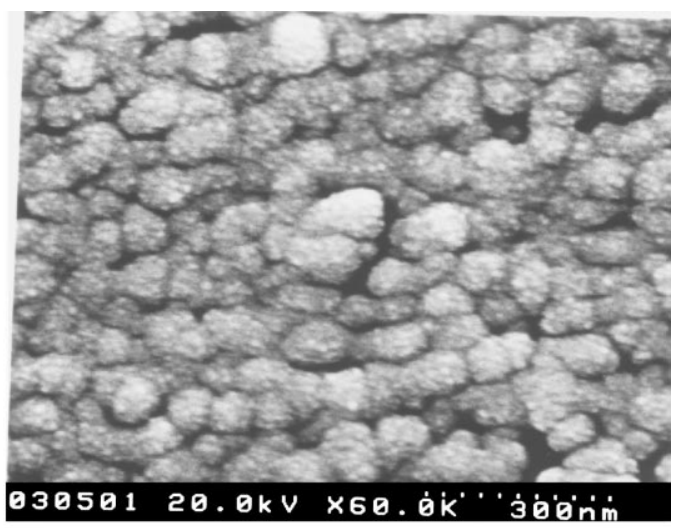

(b)

Fig. 2. SEM images of the surface nodules of membranes made from PMMA of different molecular weights: (a) 33,500, and (b) 140,000. Casting solution containing $18 \mathrm{wt} . \%$ of PMMA in NMP was casted at $90^{\circ} \mathrm{C}$. 


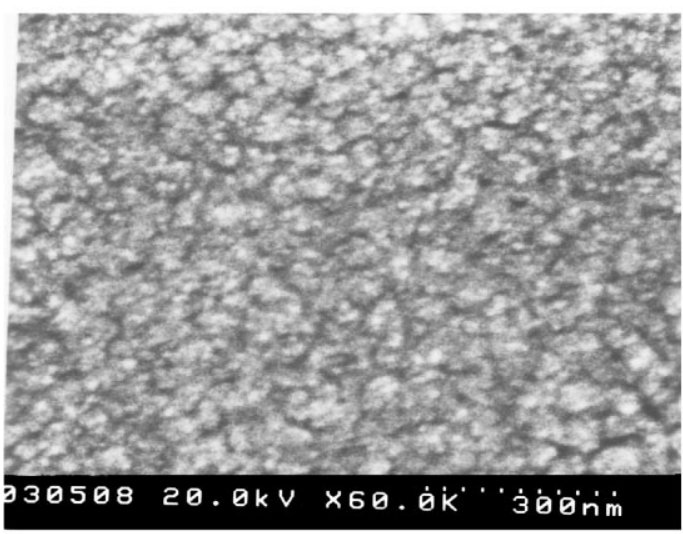

(a)

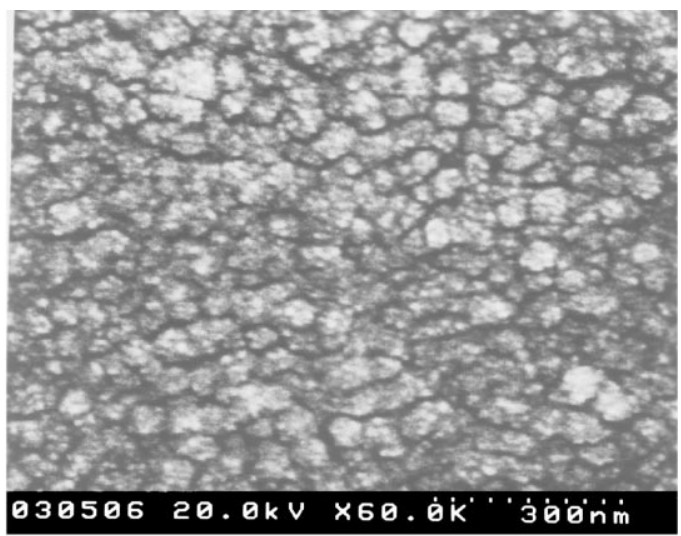

(b)

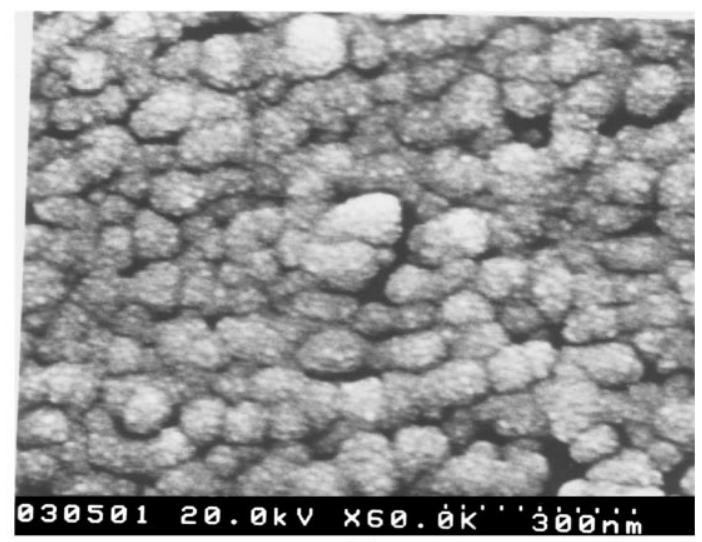

(c)

Fig. 3. SEM images of the surface nodules of PMMA membranes casted at: (a) $10^{\circ} \mathrm{C}$, (b) $50^{\circ} \mathrm{C}$, and (c) $90^{\circ} \mathrm{C}$. Casting solution contained 18 wt.\% of PMMA $\left(M_{\mathrm{W}} 140,000\right)$ in NMP.

solubility difference between DMSO and PMMA is the largest among these three systems and, therefore, the radius of gyration of PMMA in DMSO was supposedly the smallest. The largest surface nodule size of DMSO membranes indicated that there existed other factors affecting the surface nodule size besides the probability of interchain entanglement.

\subsection{Addition of nonsolvent into casting solution}

The addition of nonsolvent into casting solution was assumed to reduce the gyration radius of polymer chain. However, the surface nodule size increased when the casting solution contained nonsolvent. As shown in Fig. 5 and Table 1, the surface nodule size
Table 2

Solubility factor differences between PMMA and various solvents

\begin{tabular}{|c|c|c|c|c|}
\hline & \multicolumn{3}{|c|}{$\begin{array}{l}\text { Solubility parameter } \\
\left(\mathrm{J} / \mathrm{cm}^{3}\right)^{1 / 2}\end{array}$} & \multirow{2}{*}{$\begin{array}{l}\text { Solubility parameter } \\
\text { difference, } \delta_{\mathrm{p}-\mathrm{s}} \\
\left(\mathrm{J} / \mathrm{cm}^{3}\right)^{1 / 2}\end{array}$} \\
\hline & $\delta_{\mathrm{d}}$ & $\delta_{\mathrm{p}}$ & $\delta_{\mathrm{h}}$ & \\
\hline NMP & 17.9 & 12.3 & 7.2 & 4.68 \\
\hline DMAc & 16.8 & 11.5 & 10.2 & 4.93 \\
\hline DMSO & 18.4 & 16.4 & 10.2 & 9.32 \\
\hline PMMA & 15.7 & 8.2 & 6.7 & \\
\hline
\end{tabular}

actually increased as the nonsolvent content in the casting solution increased. It clearly indicated that the surface nodule size was not determined solely by the radius of gyration of each polymer chain. 


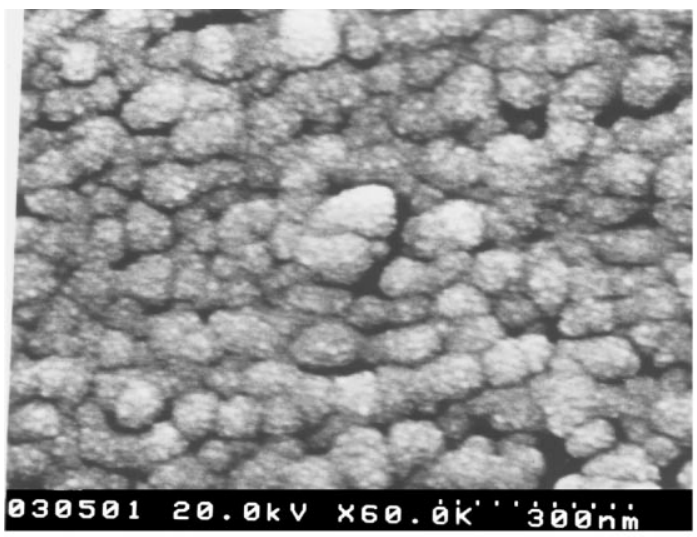

(a)

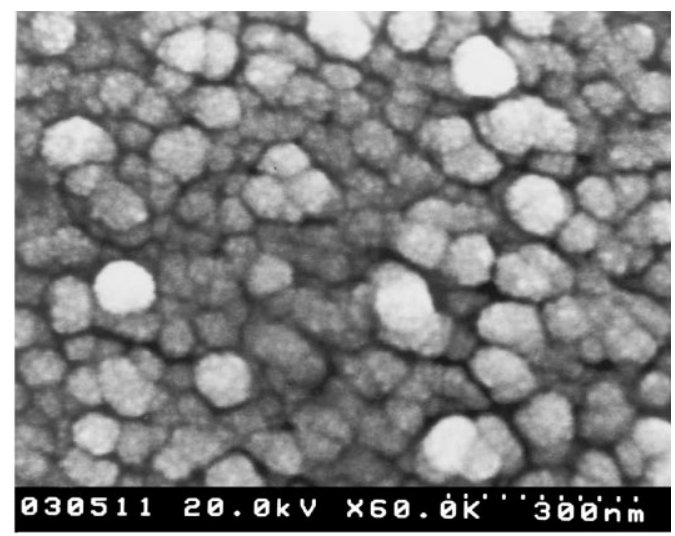

(b)

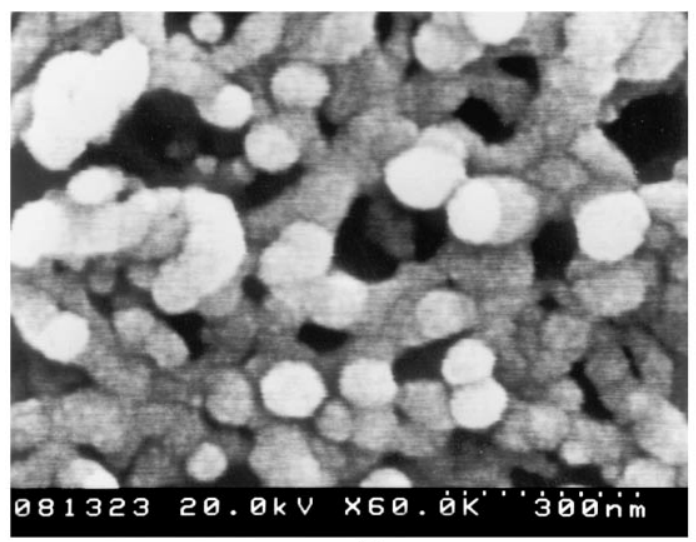

(c)

Fig. 4. SEM images of the surface nodules of PMMA membranes of which the casting solvent are: (a) NMP, (b) DMAc, and (c) DMSO. Casting solution containing $18 \mathrm{wt} . \%$ of PMMA $\left(M_{\mathrm{W}} 140,000\right)$ was casted at $90^{\circ} \mathrm{C}$.

\subsection{Effect of the interfacial tension of casting solution}

The surface tension of the casting solution may also affect the surface nodule size of a polymeric membrane. We have measured the surface tension of various casting solutions, and found that the surface nodule size increased as the surface tension increased. Table 3 lists the surface tensions of many PMMA casting solutions and the surface tension differences between casting solutions and coagulants. We have found that the surface tension increased slightly with the molecular weight of PMMA, the nonsolvent content, and the polymer concentration in the casting solution. Furthermore, the surface tension of PMMA/NMP solution was also a little bit higher than that of PMMA/DMSO solution. Kesting [2] has suggested that the increase of surface tension of casting solution tended to decrease the surface nodule size when the membranes were formed by the dry process. If the surface tension difference between casting solution and coagulant can be correlated with their interfacial tension, from this study, we also found that the increase of interfacial tension between casting solution and coagulant decreased the surface nodule size when membranes were formed by the wet phase inversion process.

\subsection{Nodule size within the membranes}

We have shown in the previous sections that in some cases the relative size of surface nodules were 


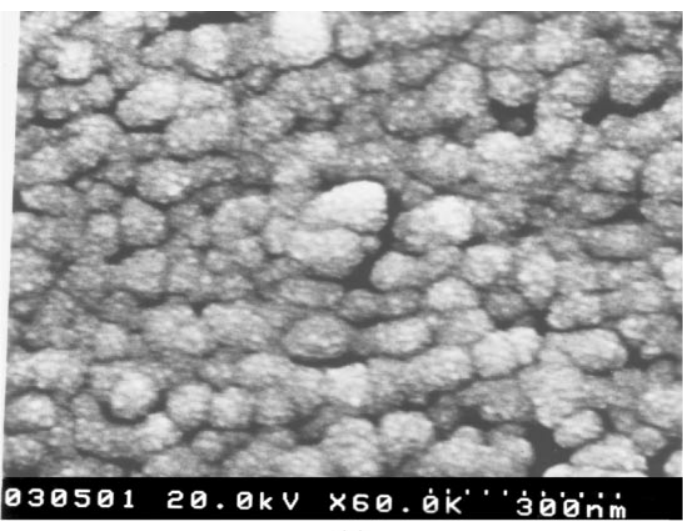

(a)

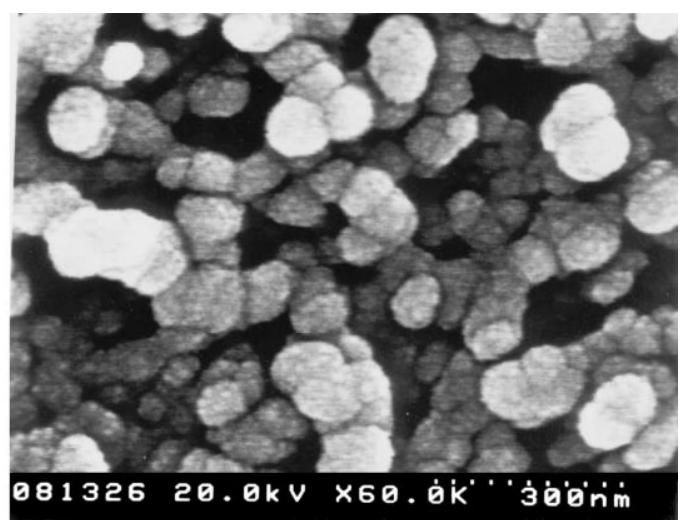

(b)

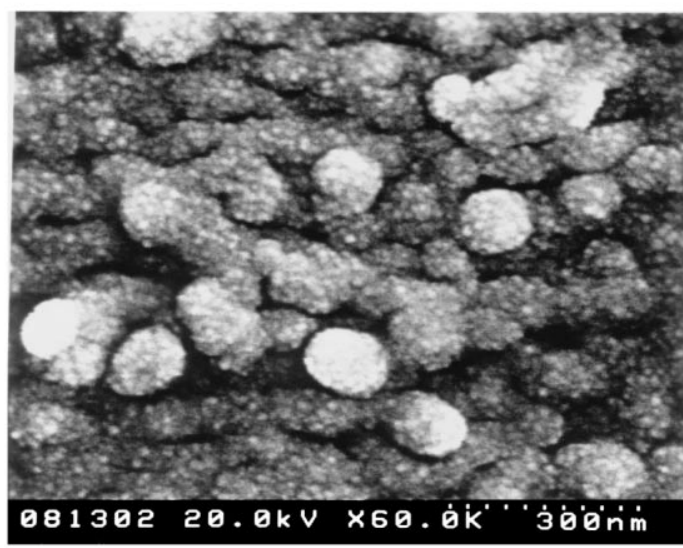

(c)

Fig. 5. SEM images of the surface nodules of PMMA membranes when the casting solution contains various amounts of nonsolvent. Casting solution contained $18 \mathrm{wt} . \%$ of PMMA $\left(M_{\mathrm{W}} 140,000\right)$ and (a) $0 \%$, (b) $2 \%$, or (c) $6 \% \mathrm{H}_{2} \mathrm{O}$ in NMP. Membranes were casted at $90^{\circ} \mathrm{C}$.

Table 3

Surface tensions of PMMA casting solutions and surface tension differences between casting solutions and coagulants

\begin{tabular}{|c|c|c|c|c|}
\hline Temperature $\left({ }^{\circ} \mathrm{C}\right)$ & Casting solution & $M_{\mathrm{W}}$ & $\begin{array}{l}\text { Surface tension, } \\
\gamma(\mathrm{mN} / \mathrm{m})\end{array}$ & $\Delta \gamma$ \\
\hline 90 & 12 wt.\% PMMA/NMP & 140,000 & 34.8 & 26.8 \\
\hline 90 & 18 wt.\% PMMA/NMP & 140,000 & 35.0 & 26.6 \\
\hline 90 & 18 wt.\% PMMA/NMP & 33,500 & 33.8 & 27.8 \\
\hline 50 & 18 wt.\% PMMA/NMP & 140,000 & 37.3 & 30.8 \\
\hline 10 & 18 wt.\% PMMA/NMP & 140,000 & 42.6 & 32.0 \\
\hline 90 & 18 wt.\% PMMA/DMSO & 140,000 & 37.8 & 23.8 \\
\hline 90 & 18 wt. $\%$ PMMA/98 vol. $\%$ NMP +2 vol. $\% \mathrm{H}_{2} \mathrm{O}$ & 140,000 & 35.7 & 25.9 \\
\hline 90 & 18 wt. $\%$ PMMA $/ 94$ vol. $\%$ NMP +6 vol. $\% \mathrm{H}_{2} \mathrm{O}$ & 140,000 & 36.4 & 25.2 \\
\hline 90 & $\mathrm{H}_{2} \mathrm{O}$ & & 61.6 & - \\
\hline 50 & $\mathrm{H}_{2} \mathrm{O}$ & & 68.1 & - \\
\hline 10 & $\mathrm{H}_{2} \mathrm{O}$ & & 74.6 & - \\
\hline
\end{tabular}


(a)
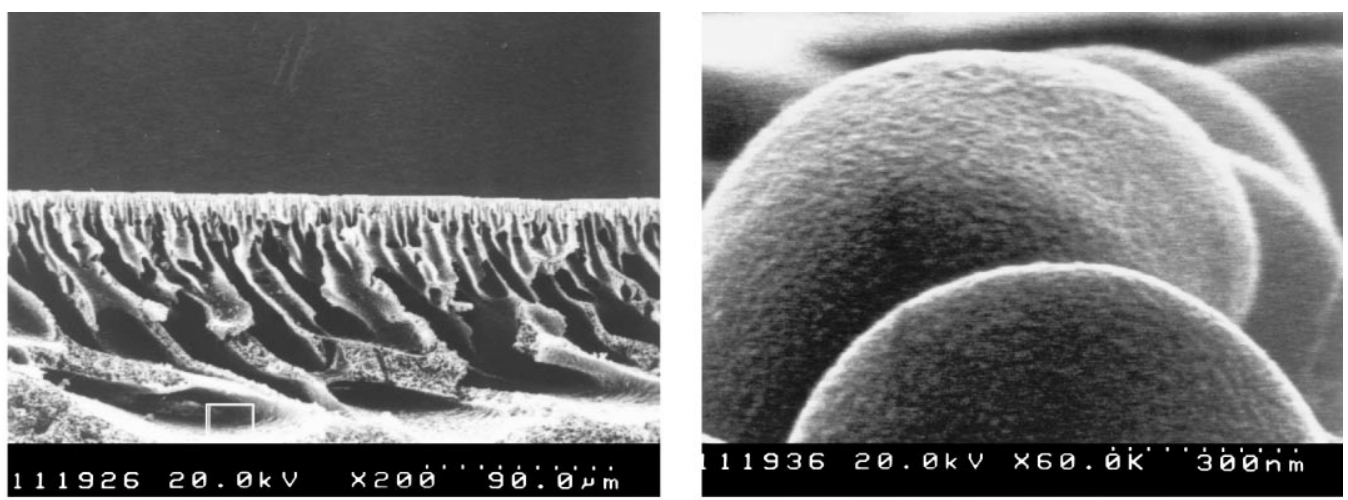

(b)
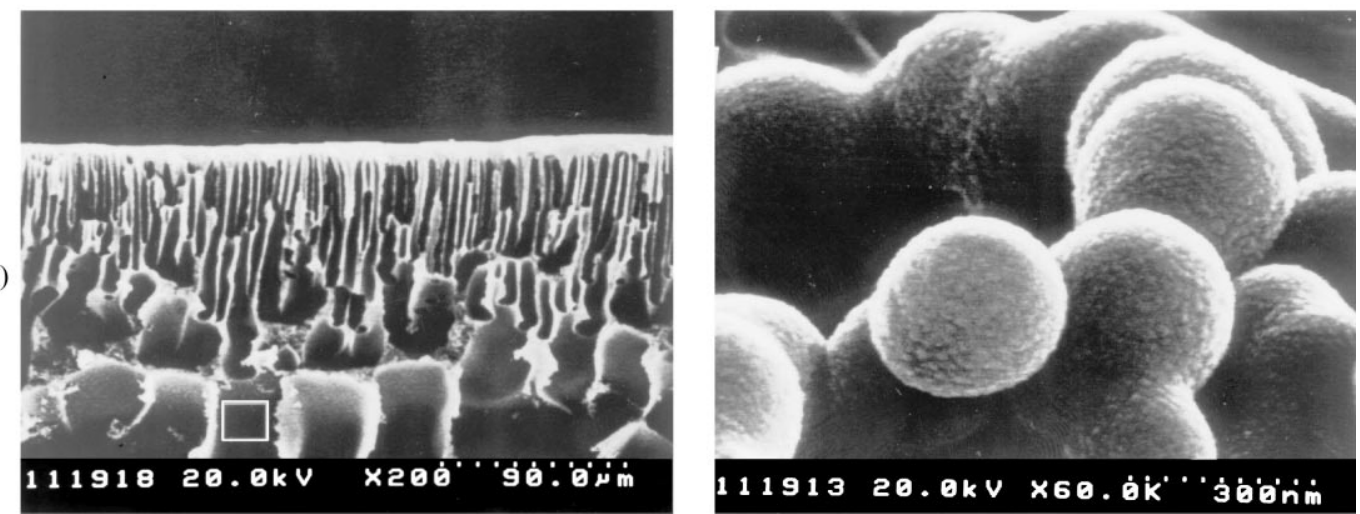

Fig. 6. SEM photographs of the cross-section of PMMA membranes using (a) NMP or (b) DMSO as the solvent. The left hand side is the $200 \times$ magnification of the cross-section and the right hand side is the $6000 \times$ magnification image. Casting solution containing $18 \mathrm{wt} \%$ of PMMA $\left(M_{\mathrm{W}} 140,000\right)$ was casted at $90^{\circ} \mathrm{C}$.

not affected by the relative radius of gyration of polymer chains. If this was truly caused by the interfacial tension, it was less likely to happen within the membranes. The nodule sizes within the membranes were, therefore, investigated. Fig. 6 shows the SEM photographs of the cross-section of PMMA membranes using NMP and DMSO as the solvents. Opposite to what was observed on the surface, the nodule size within the PMMA/NMP membrane was much larger than the PMMA/DMSO one. This result suggested that the gyration radius of polymer chains determined the nodule size when the effect of interfacial tension was not significant. Similar results were also observed when the nonsolvent was added into the casting solution before casting. Fig. 7 shows the SEM photographs of the cross-section of PMMA membranes when 2,6 , or $10 \mathrm{vol} . \%$ of $\mathrm{H}_{2} \mathrm{O}$ was added into the casting solution. It was clearly observed that the membrane formed by casting solution containing less nonsolvent had a bigger nodule size. The gyration radius of PMMA polymer was supposedly reduced after the nonsolvent was added. The cross-section information actually supported the chain entanglement hypothesis. However, as was mentioned earlier, the surface nodule size did not follow the same trend. This result suggested that the probability of interchain entanglement governed the nodule size when nodule formation was not strongly affected by interfacial tension.

\subsection{Effect of the rate of membrane formation}

It was suspected that the rate of membrane formation was also affecting the nodule size. We compared the coagulation rate of membranes casted at different conditions by their light transmission curves. Fig. 8 
(a)
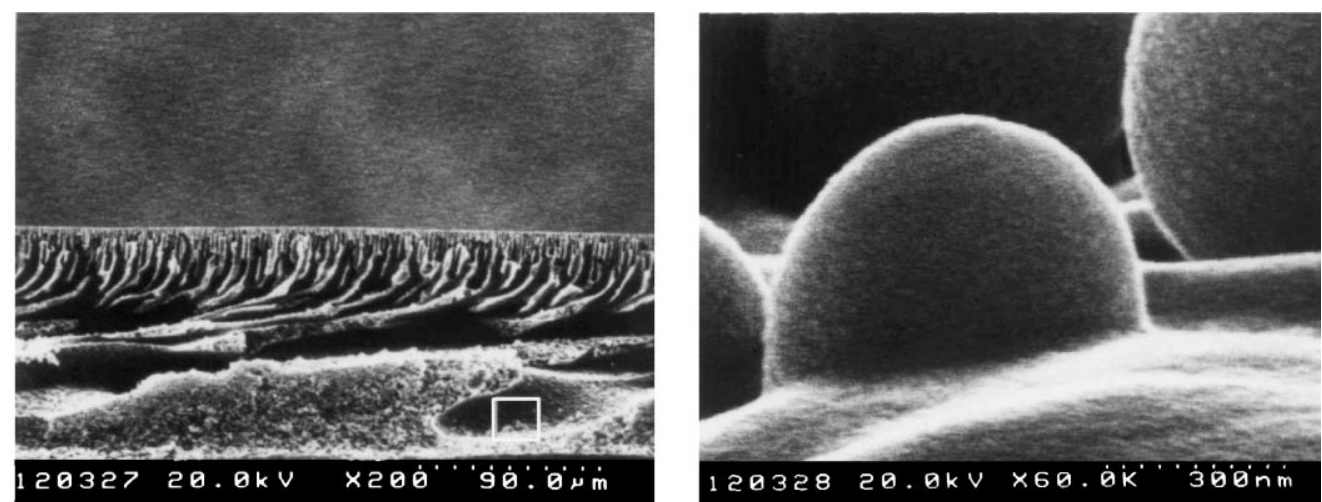

(b)
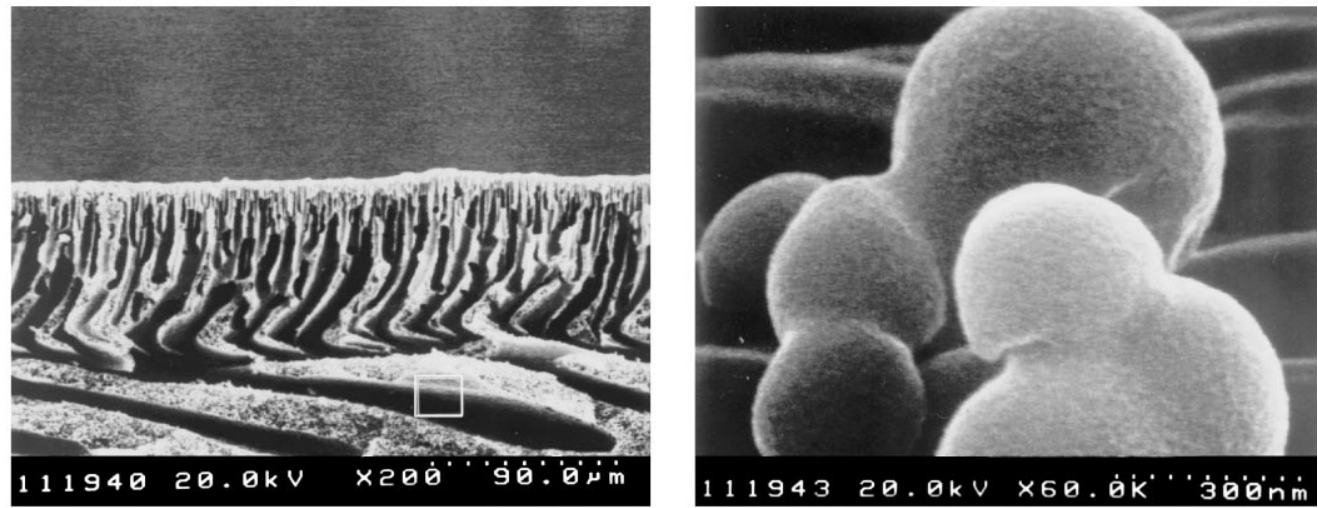

(c)
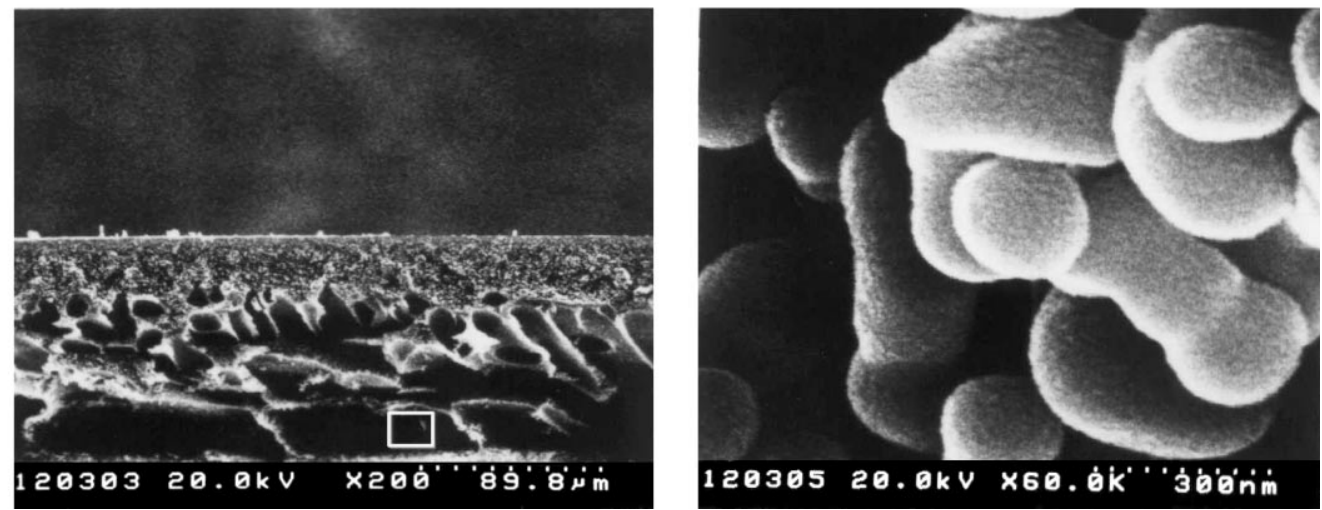

Fig. 7. SEM photographs of the cross-section of PMMA membranes when (a) 2 vol. $\%$, (b) 6 vol. $\%$, or (c) 10 vol. $\%$ water was added into the casting solution. The left hand side is the $200 \times$ magnification of the cross-section and the right hand side is the $6000 \times$ magnification image. Casting solution containing $18 \mathrm{wt} \%$ of PMMA $\left(M_{\mathrm{W}} 140,000\right)$ in NMP was casted at $90^{\circ} \mathrm{C}$.

shows the light transmission curves of membranes made of PMMA of different molecular weights $\left(M_{\mathrm{W}}\right)$. It was found that the membrane coagulated the fastest $\left(M_{\mathrm{W}} 33,500\right)$ had the smallest surface nodule size. However, when we compared the rate of membrane formation at different temperatures, as shown in Fig. 9, it was found that the fastest coagulating membrane (at $90^{\circ} \mathrm{C}$ ) had the larger surface nodule size. Apparently, the rate of membrane formation has no absolute relationship with the surface nodule size. 


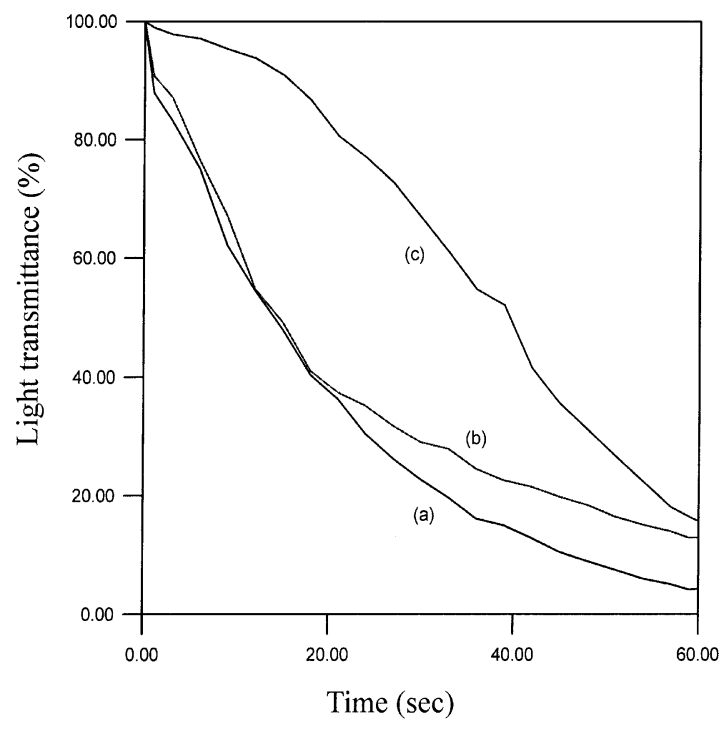

Fig. 8. Effect of the molecular weight on light transmission curves of PMMA membranes. Casting solution containing $18 \mathrm{wt} \%$ of PMMA in NMP was casted at $90^{\circ} \mathrm{C}$. The $M_{\mathrm{W}}$ of PMMA was: (a) 33,500 , (b) 140,000 , or (c) 314,400 .

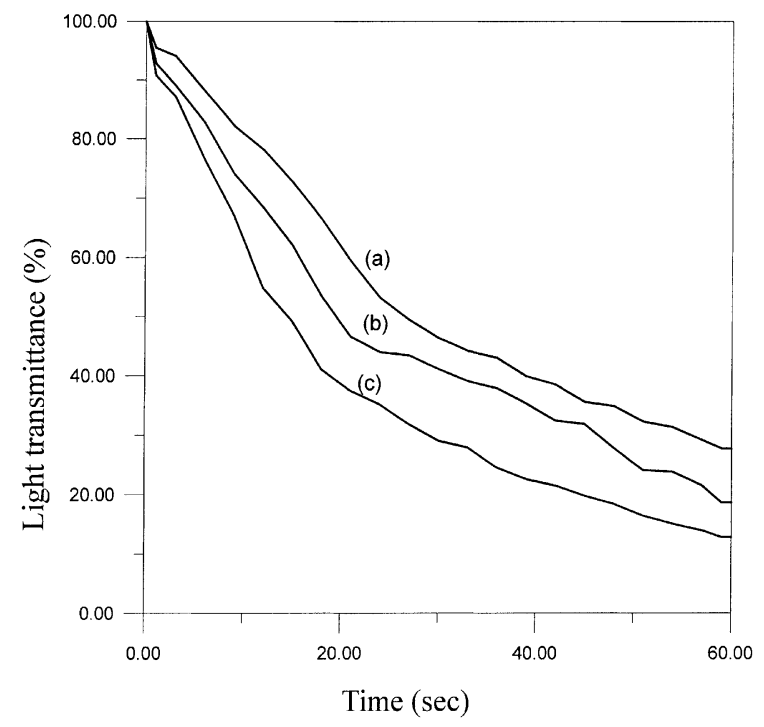

Fig. 9. Effect of the casting temperature on light transmission curves of PMMA membranes. Casting solution containing $18 \mathrm{wt} . \%$ of PMMA $\left(M_{\mathrm{W}} 140,000\right)$ in NMP was casted at: (a) $10^{\circ} \mathrm{C}$, (b) $50^{\circ} \mathrm{C}$, or (c) $90^{\circ} \mathrm{C}$.

\section{Conclusion}

The nodule sizes on the surface of PMMA membranes were compared at different casting conditions. It was found that the surface nodule size increased as the concentration of casting solution and the molecular weight of PMMA increased. We have tried to compare the nodule size of membranes prepared by two different drying procedures, vacuum-drying at $90^{\circ} \mathrm{C}$ or freeze-drying for $24 \mathrm{~h}$. No significant difference was observed. It indicated that the nodule size was determined during the wet inversion process. These data suggested that the increase of surface nodule size directly related to the radius of gyration of a single polymer chain and the concentration of the polymer. The effect of gyration radius was further supported by the results obtained at elevated temperatures. The surface nodule size increased when PMMA was casted at a higher temperature. However, when the casting solvent was changed from NMP to DMSO, a solvent of lower solvation power, the surface nodule size increased. Even more surprisingly, when nonsolvent was added into the casting solution to reduce the gyration radius of polymer chains, the surface nodule size also increased. These results indicated that the surface nodule size was affected by other factors besides the radius of gyration and the concentration of the polymer chain. After examining the cross-section of the membranes, it was found that interfacial tension might be another factor affecting surface nodule size. At the place where there was no interfacial tension, the nodule size was mainly governed by the probability of interchain entanglement. But at the surface of the membrane, where interfactial tension could not be avoided, the nodule size was controlled by the interfactial tension.

\section{Acknowledgements}

The authors wish to thank the National Science Council of ROC (NSC 89-2216-E-033-007) for the financial support.

\section{References}

[1] A.K. Fritzsche, A.R. Arevalo, M.D. Moore, C. O'Hara, The surface structure and morphology of polyacrylonitrile membranes by atomic force microscopy, J. Membr. Sci. 81 (1993) 109-120. 
[2] R.E. Kesting, The four tiers of structure in integrally skinned phase inversion membranes and their relevance to the various separation regimes, J. Appl. Polym. Sci. 41 (1990) 2739-2752.

[3] K.C. Khulbe, T. Matsuura, G. Lamarche, H.J. Kim, The morphology characterisation and performance of dense PPO membranes for gas separation, J. Membr. Sci. 135 (1997) 211-223.

[4] K.C. Khulbe, T. Matsuura, S.H. Noh, Effect of thickness of the PPO membranes on the surface morphology, J. Membr. Sci. 145 (1998) 243-251.

[5] A. Hamza, G. Chowdhury, T. Matsuura, S. Sourirajan, Sulphonated poly(2,6-dimethyl-1,4-phenylene oxide)-polyethersulphone composite membranes. Effects of composition of solvent system, used for preparing casting solution, on membrane-surface structure and reverse-osmosis performance, J. Membr. Sci. 129 (1997) 55-64.

[6] J.Y. Kim, H.K. Lee, S.C. Kim, Surface structure and phase separation mechanism of polysulfone membranes by atomic force microscopy, J. Membr. Sci. 163 (1999) $159-166$.

[7] I.M. Wienk, Th. van Den Boomgaard, C.A. Smolders, The formation of nodular structures in the top layer of ultrafiltration membranes, J. Appl. Polym. Sci. 53 (1994) 1011-1023.

[8] A.F.M. Barton, CRC Handbook of Solubility Parameters and Other Cohesion Parameters, CRC Press, Boca Raton, 1991 (Chapter 13).

[9] D.W. van Krevelen, Properties of Polymers, 3rd Edition, Elsevier, Amsterdam, 1990 (Chapter 7). 